\title{
A farm systems approach to the adoption of sustainable nitrogen management practices in California
}

\author{
Jessica Rudnick ${ }^{1,2}$ (D) Mark Lubell ${ }^{2} \cdot$ Sat Darshan S. Khalsa ${ }^{3} \cdot$ Stephanie Tatge $^{4} \cdot$ Liza Wood $^{2} \cdot$ Molly Sears $^{5}$. \\ Patrick H. Brown ${ }^{3}$
}

Accepted: 5 January 2021 / Published online: 4 February 2021

(c) The Author(s) 2021

\begin{abstract}
Improving nitrogen $(\mathrm{N})$ fertilizer management in agricultural systems is critical to meeting environmental goals while maintaining economically viable and productive food systems. This paper applies a farm systems framework to analyze how adoption of $\mathrm{N}$ management practices is related to different farming operation characteristics and the extent to which fertilizer, soil and irrigation practices are related to each other. We develop a multivariate probit regression model to analyze the interdependency of these adoption behaviors from 966 farmers across three watersheds and diverse cropping systems in the Central Valley of California. Our analysis demonstrates that farmers adopt varying combinations or portfolios of practices, with the most common portfolio featuring a core set of fertilizer-focused practices. Irrigation infrastructure is an especially important farm operation characteristic for encouraging adoption of innovative practice portfolios that integrate water and fertilizer management. These findings highlight the ability for a farm systems approach to improve our understanding of farmer decision-making across diverse agricultural landscapes.
\end{abstract}

Keywords Agricultural decision-making · Nitrogen management · Farmer adoption · Farm systems $\cdot$ Multivariate probit regression

\begin{tabular}{|c|c|c|c|}
\hline \multicolumn{2}{|c|}{ Abbreviations } & NUE & Nitrogen use efficiency \\
\hline BMP & Best management practice & QAP & Quadratic assignment procedure \\
\hline CGSP & Colusa Glenn Subwatershed Program & SJDWQC & San Joaquin County and Delta Water Quality \\
\hline ESJWQC & East San Joaquin Water Quality Coalition & & Coalition \\
\hline ET & Evapotranspiration & & \\
\hline ILRP & Irrigated Lands Regulatory Program & & \\
\hline MVP & Multivariate probit regression & & \\
\hline $\mathrm{N}$ & Nitrogen & & \\
\hline
\end{tabular}

Jessica Rudnick

jrudnick@ucsd.edu

Mark Lubell

mnlubell@ucdavis.edu

Sat Darshan S. Khalsa

sdskhalsa@ucdavis.edu

Stephanie Tatge

statge@ucdavis.edu

Liza Wood

belwood@ucdavis.edu

Molly Sears

molly_vandop@berkeley.edu

Patrick H. Brown

phbrown@ucdavis.edu
1 California Sea Grant, University of California San Diego, 9500 Gilman Dr., \#0232, La Jolla, CA 92093-0232, USA

2 Department of Environmental Science and Policy, University of California Davis, One Shields Drive, Davis, CA 995616, USA

3 Department of Plant Sciences, University of California Davis, One Shields Drive, Davis, CA 995616, USA

4 The Freshwater Trust, 1717 I St., Suite A, Sacramento, CA 95811, USA

5 Department of Agricultural and Resource Economics, University of California Berkeley, 100 Academic Hall, Berkeley, CA 94720, USA 


\section{Introduction}

Nitrogen $(\mathrm{N})$ fertilizers are a dominant input in industrialized agricultural systems, significantly enhancing crop growth and yields, while also generating one of the most challenging sources of current environmental pollution (Good and Beatty 2011; Osmond et al. 2015; Kanter et al. 2020). Excess fertilizer not taken up by the crop is susceptible to leaching, runoff and volatilization, leading to contamination of drinking water resources, ecosystem damages and release of nitrous oxide, a potent greenhouse gas (U.S. EPA 2017; Harter et al. 2012; Tomich et al. 2016). While agricultural research and extension has devoted significant attention to developing farm management strategies for improving $\mathrm{N}$ use efficiency (NUE), understanding the factors influencing farmers' adoption of these practices remains an active area of agricultural social science research (Reimer et al. 2017). Moreover, a growing body of ecological modelling research suggests that it will be necessary in most circumstances to simultaneously implement multiple best management practices, in order to see the desired improvements in ecological and social outcomes (Bosch et al. 2013; Teshager et al. 2017; McLellan et al. 2018). Yet, every practice will not necessarily be efficient or effective under the ecological or operational conditions of every farm, thus farmers must ultimately be able to determine the practices that best fit their unique context and tailor a portfolio of practices across their farm that work together synergistically to improve $\mathrm{N}$ management.

This paper develops a conceptual and analytical framework that encompasses two problems related to the complexity of $\mathrm{N}$ management and vexed agricultural policies that incentivize or mandate practice adoption. First, management practices across a farm are interdependent and therefore it is important to analyze the mix or portfolio of practices farmers use to meet their management goals. Thus, research must move beyond analyzing only a single practice at a time or counting multiple practices in ways that do not account for interdependencies.

Second, not every practice or portfolio of practices will be effective under the ecological or operational conditions of every farm. Thus policies that encourage widespread adoption of a specific practice or as many practices as possible, do not adequately account for different farming contexts. The heterogeneity of practice benefits and costs across different agro-ecological contexts contributes to the inconsistent empirical results in terms of what farm operation and operator factors predict practice adoption (Knowler and Bradshaw 2007; Prokopy et al. 2008, 2019; Baumgart-Getz et al. 2012; Wauters and Mathijs 2014; Ulrich-Schad et al. 2017; Liu et al. 2018).
To address these problems, we apply a 'farm systems' framework that envisions farming operations as complex systems in which multiple parts or subsystems of the farm are interrelated and interdependent, such that change in one part of the system is likely to induce change in another (Giller 2013; Shaner et al. 2019). The concept of farm systems has emerged over time in agricultural development and agroecology literatures, usually with an emphasis on the importance of interdisciplinary research and recognition of the multiple biophysical, ecological, social and economic factors at play in agricultural systems (Norman 1980; van Rooyen 1984; Bawden 1995; Snapp and Pound 2008; Giller 2013; Shaner et al. 2019). However, this integrated approach remains rather nascent in applied farmer behavior and adoption research (Church et al. 2020). This paper aims to reconcile this gap by applying a farm systems framework to evaluate farmers' adoption of a suite of $\mathrm{N}$ management practices, paying careful attention to both the interdependency between individual management practices and how practice portfolios vary across farm types.

This study is grounded in the empirical context of the Central Valley of California, where $\mathrm{N}$ management has become a key focus of the state given extensive nitrate pollution in groundwater resources and associated threats to drinking water (Harter et al. 2012). The diversity in agronomic, economic and ecological factors across the region allow us to test two core hypotheses. First, farmers adopt portfolios of practices that reflect interdependencies, with practices in the same farm management area (e.g. fertilizer, soil, irrigation) more likely to be co-adopted. Second, the benefits and costs of practices, and thus the portfolio adopted, vary across heterogeneous agronomic, economic and ecological conditions that shape different farm operations. While these hypotheses do not exhaust the possible implications of a farm systems framework, they are important initial ideas applying the idea of farm systems to farmer adoption on $\mathrm{N}$ management.

The remainder of this article is organized as follows: we situate our farm systems study on $\mathrm{N}$ management within the context of broader adoption literature and develop our two core hypotheses related to $\mathrm{N}$ management in California. We then provide more details on our study context and research design, which relies on survey data from 966 farmers in three watersheds of California's Central Valley. We describe a statistical analysis method, called multivariate probit regression, which allows us to estimate the probability a farmer adopts different individual practices, accounting for interdependence among those practices. This statistical framework allows us to better capture these interdependences and go beyond analyses that look at practices in isolation or as a simple sum or index. The results focus on which portfolios of practices are likely to be co-adopted, and how farm operation characteristics, especially related to irrigation 
systems, impact the portfolio adoption decisions of different farms. The conclusion discusses theoretical and policy implications of applying the farm systems perspective.

\section{Theory and hypotheses: linking farm systems to nitrogen management practices}

The concept of farm systems research has played an important role across agricultural development and agroecology fields (Fresco and Westphal 1988; Snapp and Pound 2008; Giller 2013; Shaner et al. 2019), with the farm system being defined as "a complex interaction of soils, water sources, crops, livestock, labour, and other resources and characteristics within an environmental setting which the farm family manages in accordance with its preferences, capabilities and available technologies" (Shaner et al. 1982). Farm systems approaches emphasize interdisciplinarity to understand interdependence between different parts of a farm and different characteristics of the farmer, and integrate farmers throughout the research process to translate results to extension, outreach, policy and management goals (van Rooyen 1984).

While some recent work on sustainable agriculture has explored integrated mental models and systems thinking (Levy et al. 2018; Halbrendt et al. 2014; Hoffman et al. 2014), the farms system perspective has not been widely embraced in the applied social science research on farmer decision-making and conservation practice adoption (Church et al. 2020). Instead, much of the research on best management practice (BMP) adoption emphasizes theories of decision making on a single action, like Diffusion of Innovation (Rogers 2003) or Theory of Planned Behavior (Ajzen 1989). Often these studies set the dependent variable as the adoption of one practice or an index composed of multiple practices, and independent variables are some mix of farmer demographics, attitudes, perceptions and farm operation characteristics (Prokopy et al. 2019; Ranjan et al. 2019). We aim to apply the farm systems framework to understand how farmers consider relationships between practices and how the specific characteristics of a practice influence its adoptability on different types of farms (Reimer et al. 2012a).

$\mathrm{N}$ management is a clear case demanding the application of a farm systems approach. A substantial body of agronomic research has developed tools to approximate crop $\mathrm{N}$ demand and recommend best management practices that reduce N losses (Snyder 2017; Khalsa and Brown 2019). For example, the "4Rs" conceptual framework ("Right rate", "Right time", "Right place", and "Right source") offers farmers and farm advisors a decision support tool to adjust fertilizer applications (Mikkelsen 2011). More recently, research has highlighted how other aspects of the farm, especially soil and irrigation management, influence the balance between crop $\mathrm{N}$ demand and $\mathrm{N}$ losses (Denny et al. 2019; Snyder 2017). Thus, effective N management will require a portfolio of management practices that influence different management areas of the farm, tailored to the combination of ecological, agronomic and economic dimensions of a specific operation, all of which can influence how a management practice works.

We draw on this literature to analyze two hypotheses: adoption decisions on multiple practices are interdependent with one another $(\mathrm{H} 1)$ and adoption of portfolios of practices vary across farming operation characteristics (H2). These hypotheses are tested in the empirical context of California, which provides a diverse agricultural landscape with production of both annual and perennial commodities, farms ranging in scale and structure from small acreage, family-owned to very large acreage, corporate operations, and a complex hydrologic system where farmers irrigate using both surface and groundwater and a variety of irrigation technologies. We evaluate farmer's adoption decisions of eight different $\mathrm{N}$ management practices across three farm management areas: fertilizer, soil, and irrigation (See Table 1 for descriptions of practices).

\section{Hypothesis 1: interdependence of practice adoption}

Interdependence across system components is one of the most fundamental premises of any systems approach. Within a farm system, interdependence is present across different aspects of the farm and the management practices employed. In the context of $\mathrm{N}$ management specifically, $\mathrm{N}$ availability and $\mathrm{N}$ losses depend on applications of $\mathrm{N}$ fertilizer to crops, irrigation management which may introduce additional $\mathrm{N}$ from nitrate-contaminated groundwater or push $\mathrm{N}$ through the soil profile, and soil management which may introduce organic N sources (e.g. compost, cover crops) or influence soil properties that relate to nutrient retention (Khalsa et al. 2018). Furthermore, ecosystem modelling suggests portfolios of practices will be necessary in order to reduce $\mathrm{N}$ losses enough to have a positive impact on water quality (Bosch et al. 2013; Teshager et al. 2017; Denny et al. 2019).

Portfolio approaches have been applied to measure the relationships between adoption decisions to estimate which practices are complementary (i.e. work in congruence with one another to enhance efficacy), conflictual (i.e. result in worse outcomes when used together) or substitutable (i.e. redundant; one can replace the use of the other) with others in contributing to a management goal (McAllister et al. 2009; Teklewold et al. 2013; Kassie et al. 2015; Zulfiqar et al. 2016; Murendo et al. 2016; Koppmair et al. 2017). From a decision-making perspective, co-adoption of multiple practices may be linked through multiple mechanisms, such as information sources that jointly recommend related practices (Tucker and Napier 2002), farmer experimentation 
Table 1 Descriptions of $\mathrm{N}$ management practices evaluated in study, including the management area of the farm with which the practice is typically associated

\begin{tabular}{|c|c|c|}
\hline Practice name & Description & $\begin{array}{l}\text { Farm } \\
\text { management } \\
\text { area }\end{array}$ \\
\hline Leaf testing & Test crop leaf for crop nutrient status to determine if plant is up-taking enough nutrients & Fertilizer \\
\hline Split application & $\begin{array}{l}\text { Divide fertilizer applications into smaller doses and apply in different applications at needed } \\
\text { times in season }\end{array}$ & Fertilizer \\
\hline Soil testing & $\begin{array}{l}\text { Test soil for residual nitrate at beginning of season and adjust fertilizer application rate as } \\
\text { appropriate }\end{array}$ & Fertilizer \\
\hline Irrigation well $\mathrm{N}$ testing & Test irrigation water in wells for nitrate content and adjust fertilizer application rates as needed & Fertilizer \\
\hline Cover crops & $\begin{array}{l}\text { Plant cover crops to help hold moisture and nutrients in the soil; provides an organic source of } \\
\text { nitrogen that breaks down more slowly over time }\end{array}$ & Soil \\
\hline Moisture probe & $\begin{array}{l}\text { Test soil water content to determine depth of soil saturation and more precisely control irriga- } \\
\text { tion to give crop just enough water, which still retaining fertilizer in root zone }\end{array}$ & Irrigation \\
\hline Pressure bomb & $\begin{array}{l}\text { Determine plant-water stress and adjust irrigation scheduling as appropriate, including when } \\
\text { fertilizer is applied so that fertilizer stays in root zone }\end{array}$ & Irrigation \\
\hline ET-based irrigation scheduling & $\begin{array}{l}\text { Use evapotranspiration (ET) data to determine plant water losses, and calculate how much } \\
\text { water needs to be replaced with irrigation. Appropriately place fertilizer in the irrigation set } \\
\text { so that fertilizer stays in root zone }\end{array}$ & Irrigation \\
\hline
\end{tabular}

with multiple practices (Pannell et al. 2006), the adoption of one practice lowering the perceived risk or cost of another practice (Feder 1982), technical knowledge 'spillovers' that contribute to a better understanding of an additional practice (Conley and Udry 2010), co-dependence or use of the same farm infrastructure (Hanson et al. 2009), or increased sophistication that drives the farmer to use information from one practice to amend their use of another practice (Aubert et al. 2012).

While our data does not allow us to test these mechanisms explicitly, we draw on our interdisciplinary understanding of $\mathrm{N}$ management in California to hypothesize which practices may be more frequently co-adopted. The relevant $\mathrm{N}$ management practices for which we measure adoption (see Table 1) were identified by University of California Cooperative Extension farm advisors and experts in nutrient management. Direct $\mathrm{N}$ fertilizer application and monitoring practices have traditionally been a strong emphasis of extension, including the 4R's principles and monitoring nutrient availability in the plant-soil system. As a result, we predict farmers have adopted these practices at higher rates and have better knowledge of their interdependencies. In contrast, attention toward irrigation and soil management practices has been more recent, as improved understandings and technologies to monitor nutrient movement throughout the agro-ecosystem have been developed (Coates et al. 2005; Khalsa and Brown 2017; Schellenberg et al. 2009; Fernández and Brown 2013). The extent to which irrigation practices influence $\mathrm{N}$ losses also depends heavily on the farm's water source, soil type and irrigation infrastructure in place, complicating the ability for farm advisers to make general practice recommendations around irrigation. This potential disconnect between fertilizer application and water management is exacerbated further by modern, large scale farm operations where often there are specialized teams of employees and consultants that oversee different areas of the operation, with little interaction (Kling and Mackie 2019).

With these considerations, we hypothesize (H1) that fertilizer management practices will be at the core of practice adoption portfolios (i.e. higher adoption and co-adoption with each other), with irrigation management practices at the periphery (i.e. lower adoption and co-adoption rates).

\section{Hypothesis 2: practice portfolios fit farming operation characteristics}

The complexity of the ecological and agronomic processes that shape $\mathrm{N}$ management make it such that there is no panacea, or 'one-size-fits-all' approach to the selection of appropriate management practices. The portfolio of management practices responds to site-specific farm characteristics that influence operational compatibility and economic feasibility. This site-specificity is not unique to $\mathrm{N}$ management; for example, a study in different regions of China found that conservation management practices broadly have different impacts on crop yields and conservation goals under different climate conditions and cropping systems (Zheng et al. 2014). The results suggest that farmers must adapt their selection of management practices, and subsequently practice portfolios, to 'fit' their specific operations to achieve intended results.

Unlike Midwest agricultural landscapes dominated by staple field crops (USDA Midwest Climate Hub 2017), California features a diverse agricultural landscape which 
provides an excellent research system for analyzing how portfolios of practices may vary in their fit with different types of farms (Lopus et al. 2010; Shaffer 2013). Farm size is one of the most consistent predictors of practice adoption (Prokopy et al. 2019), based on the argument that larger farms have more financial capital and economics of scale, which reduces barriers to practice adoption associated with cost, time to return on investment, and risk (Feder and Umali 1993; Ghadim et al. 2005; Kipling et al. 2019). California farm operations also feature crops across the "crop hierarchy", from low-value annuals to high-value perennials (Blank 2001). High-value perennial crop systems like fruit and nut orchards, are increasingly replacing low-value annuals in California (Howitt et al. 2008), and receive a higher return on investment for implementing practices that increase efficiency or have yield gains.

The California context also offers the opportunity to study the effect of irrigation infrastructure on practice adoption. The state's year-round growing season and Mediterranean climate (i.e. dry summers, wet winters) creates reliance on irrigation, encouraging many combinations of irrigation systems and water sources, from gravity-fed flood irrigation to systems with pressurized drip or sprinkler infrastructure, fed by surface or groundwater. Irrigation systems can have a large influence over N leaching (Letey and Vaughan 2013), and different systems may be more or less compatible with different practices. Drip irrigation systems have been widely adopted in California's perennial nut crops and high value annual crops, particularly on farms with sandy soils that rely on groundwater (Taylor and Zilberman 2017). Some N management practices are implemented more easily through drip irrigation systems, like split application where the farmer can deliver fertilizer sets through the drip irrigation, providing a low-labor way to distribute fertilizer throughout the season. Other practices have co-evolved with the diffusion of drip irrigation, like adjusting irrigation rates according to evapotranspiration (ET) estimates of crop water needs (Hanson et al. 2009; Taylor and Zilberman 2017). As a result, farmers working in operations with pressurized irrigation infrastructure may find their operations more compatible with the aforementioned practices, whereas farmers working with gravity fed irrigation systems may show a propensity toward a different suite of practices.

In considering how management practices may vary due to underlying differences in farm attributes, we hypothesize (H2) that individual practices and practice portfolios will be distinguishable across different farm types, based on crop type, farm size, irrigation system and water source characteristics.

\section{Research design}

\section{Research context: nitrogen management in California's Central Valley}

California ranks as the most economically valuable agricultural state in the United States by annual crop cash sales. The state boasts more than 400 commodity crops grown across 77,000 farms and ranches on 25 million acres of land, spread along a 500 mile longitudinal gradient (California Department of Food and Agriculture 2018). The Mediterranean climate is ideal for perennial and annual crops in most areas of the state, yet creates reliance on irrigation and a highly engineered water system. Top commodities include dairy, grapes, almonds, berries, livestock, lettuce, walnuts, tomatoes, pistachios and citrus. Farms also vary widely in scale and structure-from small and mid-sized family-owned operations to very large, multi-commodity international corporations (California Department of Food and Agriculture 2018).

Importantly for our focus on $\mathrm{N}$ management, California is one of the first states in the U.S. to implement an agricultural non-point source pollution regulatory program, the Irrigated Lands Regulatory Program (ILRP). The ILRP is implemented through local entities known as "Water Quality Coalitions" and includes mandatory elements around reporting use of best management practices and an $\mathrm{N}$ budget, as well as attendance at one educational meeting per year, held in each Water Quality Coalition (Central Valley Regional Water Quality Control Board 2020; for more information, see Online Appendix). The $\mathrm{N}$ management practices we study in this paper are consistent with those tracked as part of the ILRP mandatory reporting. This policy landscape offers a unique context to study the potential effects of governance on farmer decision-making, compared to well-documented studies evaluating practice adoption under voluntary policy settings (Reimer et al. 2018; Hillis et al. 2018).

\section{Survey and data collection}

This paper employs data collected through a mail survey conducted in 2018 across the Central Valley of California. The project integrated stakeholder feedback throughout the research process and included multiple phases of interviews, focus groups, and preliminary survey data collection that both informed our survey design and dissemination strategy, and helped in interpreting results. An external advisory committee, representing policymakers, farmers, directors of the Water Quality Coalitions, and nationwide researchers and extension specialists also provided survey 
review. Institutional Review Board approval for the study was obtained through the University of California Davis.

The survey was distributed to farmer members from three Water Quality Coalitions: the Colusa Glenn Subwatershed Program (CGSP), the San Joaquin County and Delta Water Quality Coalition (SJDWQC), and the East San Joaquin Water Quality Coalition (ESJWQC) (see Fig. 1). Together, these Coalitions covered over 900,000 acres of irrigated cropland and approximately 7500 individual farming operations in 2017. These regions represent a longitudinal transect of the Central Valley that captures a range of agricultural, ecological and socio-political dimensions. The most important crop types in these regions include almonds, walnuts, grapes, tomatoes, sunflowers, pistachios, alfalfa, corn and wheat. Rice is also a top production crop in the CGSP region, but was removed from our sampling frame since our management practices focus on non-flooded cropping systems.

Mailing addresses were provided by CGSP, to which the survey was sent to all members $(n=1471)$. In SJDWQC and ESJWQC, mailing addresses were obtained from county Agricultural Commissioner offices, who maintain publically-available databases of all commercial farming operations in compliance with Pesticide Use Reporting requirements. In these regions, organic farmer addresses were also obtained through the U.S. Department of Agriculture Organic INTEGRITY Database (United States
Department of Agriculture 2018). We removed all obvious non-agricultural entries (e.g. golf courses or public lands using pesticides) from the mailing lists. This list contained our best estimate of all eligible farmers who would report to SJDWQC or ESJWQC under the ILRP. The survey was sent to all farmers in SJDWQC region $(\mathrm{n}=2322)$ and to a random sample of $33 \%$ of farmers in ESJWQC region $(n=1243)$, due to the size of the Coalition. In aggregate, this totaled 4994 surveys mailed across all three regions.

We followed a four-wave mailing process using a modified Tailored Design Method, which included a cover letter and survey, followed by a reminder postcard, then second letter and survey, and final reminder postcard (Dillman et al. 2008). In CGSP, the Coalition permitted us access to join our survey response data to their anonymized mandatory reporting data on management practices adopted on each field. These data allowed us to compare survey-reported practice adoption rates with adoption rates reported on mandatory paperwork by farmers who did not respond to the survey, offering opportunity to evaluate the self-selection bias that is prevalent in survey-based research. We found that adoption rates did not differ between survey respondents and non-respondents, thus indicating our survey respondents were representative of adoption behavior occurring across the watershed (see Online Appendix Table A1).
Fig. 1 Map of Central Valley of California, highlighting three Water Quality Coalitions where survey was distributed

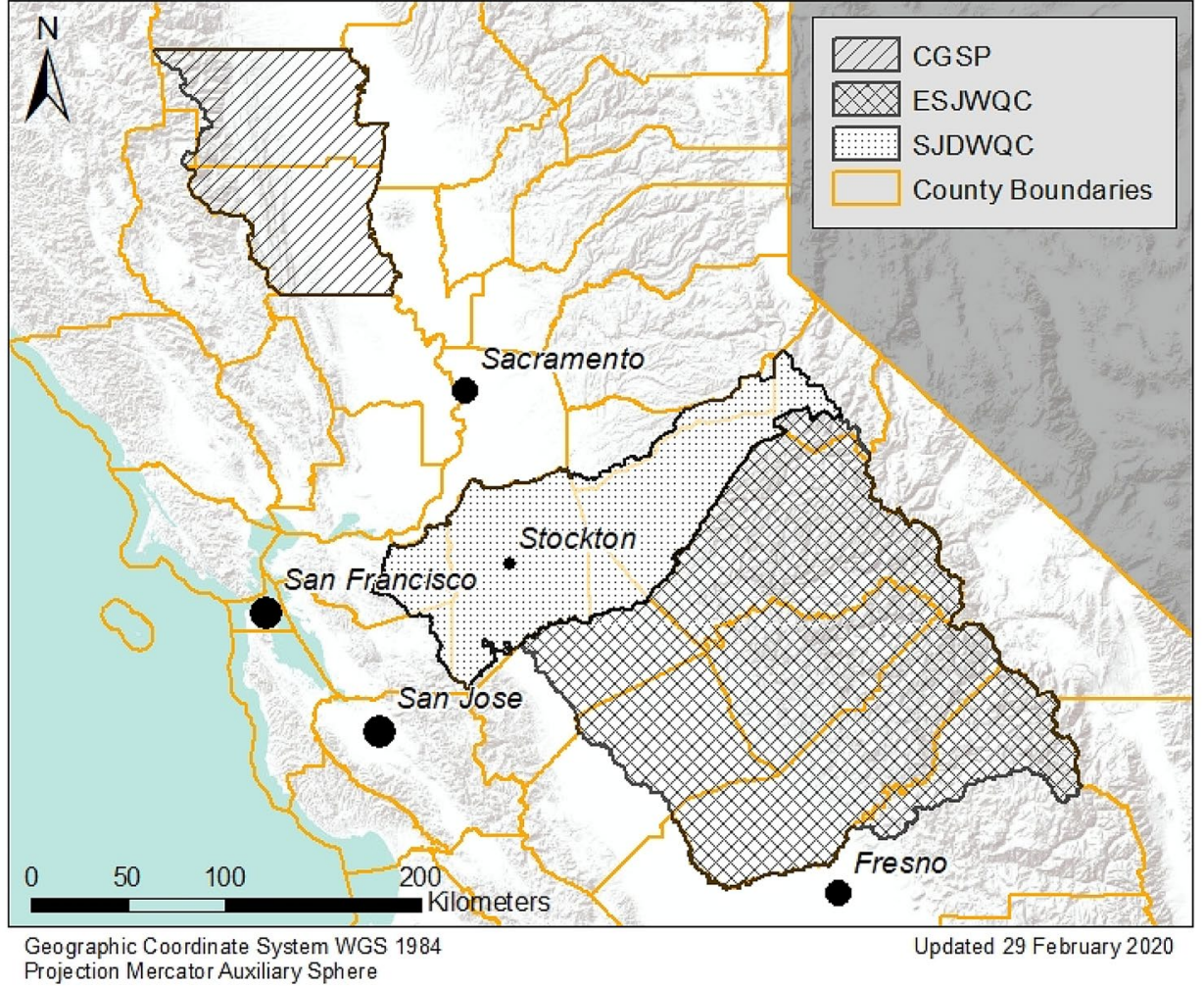




\section{Variable measurement}

The survey questionnaire included 30 questions covering a range of topics related to farmers' views on $\mathrm{N}$ management, including their adoption of eight different $\mathrm{N}$ management practices on their largest parcel of their most important crop in the 2017 crop year, measured as a binary variable. In this paper, we treat these eight $\mathrm{N}$ management practices as the simultaneous adoption outcome variables in a multivariate probit regression model.

The binary measurement of these practices is a data limitation of this paper, especially for practices that are applied in a temporally (e.g. multiple times/year versus every other year) or spatially (e.g. full operation versus particular fields) heterogeneous fashion. Given the known heterogeneity of operations on our mailing lists (e.g. operations varied from a single crop up to 14 unique crops, and from $<1$ acre to $>20,000$ acres), we were constrained to developing a survey tool that was general enough to fit every possible respondent. Furthermore, the ILRP collects practice adoption data in a binary fashion as well. Thus, aligning our data structure with that of the regulatory program allows us the best opportunity for data comparisons and to draw policyrelevant conclusions.

The survey measured farm operation characteristic variables of interest: most important crop type (aggregated into a binary variable: perennial/annual crop), farm size (logtransformed), primary irrigation type (aggregated into a binary variable: pressurized systems- drip, micro-sprinkler, versus gravity-fed systems- flood, furrow, border strip) and water source (aggregated into two binary variables: access to surface water versus groundwater, and access to both water sources versus single source).

We also measured a number of behavioral variables typically used in agricultural adoption research to include as controls (Prokopy et al. 2019). These included informationrelated variables measuring access to information from three perspectives: a tally of the total number $\mathrm{N}$ management information sources, a binary variable for the use of Certified Crop Advisers to create N budgets ("consultants"), and a binary variable for the completion of a Self-Certification course, which is a voluntary educational component of the ILRP which allows farmers to self-certify their own $\mathrm{N}$ budgets. Socio-behavioral concepts included problem awareness ("acceptance of agricultural N sources"), environmental values ("conservation motivation"), and perceived behavioral control ("self-efficacy") (Reimer et al. 2012b). These latent variables were constructed using exploratory factor analysis to combine multiple survey question items measured on five-point Likert scales (Costello and Osborne 2005), which improves reliability (McIver and Carmines 1981; DeVellis 2003; Santos 1999). Cronbach alpha scores were used to verify internal consistency between the items combined in a composite variable; all alpha scores were $>$ 0.70 , a widely-accepted cut-off to indicate internal validity (Santos and Reynaldo 1999). See Online Appendix Table A2 for information on survey questions and composite variables.

Finally, farmer demographic variables included a binary variable for college education, a categorical variable for income class, and a continuous variable for years in agriculture. Binary variables were included to distinguish the three Water Quality Coalitions, with the baseline as farmers who didn't identify with the three Coalitions of focus or left the question unanswered.

\section{Survey respondents}

We received a total of 966 partial and full survey responses back (CGSP: $\mathrm{n}=377$, SJDWQC: $\mathrm{n}=312$, ESJWQC: $\mathrm{n}=183$ ), constituting an average response rate of $20 \%$ (CGSP: $30.7 \%$ SJDWQC: $14.4 \%$, ESJWQC: $15.4 \%$ ). We removed 101 responses from farmers reporting on irrigated pasture, bringing our useable number of respondents to 865 . Response rates were adjusted for the possible non-eligible addresses included in our original mailing lists (American Association for Public Opinion Research 2016). Our response rate is on par with recent surveys using similar designs and regarding similar topics (Denny et al. 2019; Wilson et al. 2014; Arbuckle and Rosman 2014). All survey data was digitized for analysis.

Respondents are fairly representative of the full farming populations in the surveyed regions, when compared to USDA 2012 Census of Agriculture data (see Online Appendix Tables A3-A5). The average farm size of our respondents is 355 acres (minimum $<1$ acre, maximum $\sim 12,000$ acres). In aggregate, our survey respondents manage 329,800 acres of land across the Central Valley, approximately 35\% of the acreage of the study area. Seventy-nine percent of respondents own their land; $80 \%$ of respondents are male; $84 \%$ of respondents identify as White or Caucasian, $4 \%$ as Hispanic or Latino and 3\% as Asian or Asian American. Sixty-one percent of respondents have at least some college education. On average, respondents have 35 years of farming experience, and the median gross farm income bracket is $\$ 100,000-\$ 200,000$.

Respondents listed all crops and acreage they cultivate, though we only asked about practice adoption on their most important crop, as self-identified on the survey. Sixty-four percent of farmers report only growing one crop, $27 \%$ two to four crops, and $4 \%$ have five or more crops. Eighty-five percent of respondents indicate a perennial crop as their most important. Seventy-four percent of respondents have pressurized irrigation systems on their most important parcels. Forty percent of respondents rely on groundwater only, $44 \%$ have access to surface water (only) through riparian rights or irrigation district delivery water, and $16 \%$ have both surface 
and groundwater access (See Online Appendix Table A6 for all descriptive statistics).

\section{Analysis approach: multivariate probit for estimating interdependencies}

Much of the existing adoption literature uses a standard quantitative approach of estimating some type of linear model with an individual practice, or count of practices, as the dependent variable, and multiple predictor variables to test hypotheses about drivers of adoption (Prokopy et al. 2019). Here, we need an empirical model that simultaneously estimates farm and farmer variable influences on the adoption of multiple practices, and how those practices are related to each other. To accomplish this goal, we employ a multivariate probit (MVP) model that allows estimation of multiple binary probit regression models (in our case 8 models) simultaneously, while analyzing correlation between errors in the different models. Failure to account for these correlated error terms can result in inefficient coefficient estimates and biased error terms (Cappellari and Jenkins 2003). This approach has been applied in other studies looking at simultaneous adoption in developing agricultural settings (Koppmair et al. 2017; Kassie et al. 2015; Kara et al. 2008; Teklewold et al. 2013; Jara-Rojas et al. 2013).

Considering all $\mathrm{N}$ management practices, each equation in the system can be written as:

$$
\begin{aligned}
\boldsymbol{Y}^{*}{ }_{i} & =\boldsymbol{B}_{1 i} \boldsymbol{X}_{\boldsymbol{a}}+\boldsymbol{B}_{2 i} \boldsymbol{X}_{\boldsymbol{b}} \ldots \boldsymbol{B}_{n i} \boldsymbol{X}_{\boldsymbol{n}}+\boldsymbol{e}, \\
(i & =L T, S T, C C, I N, M P, S A, P B, E T),
\end{aligned}
$$

where $\boldsymbol{Y}_{\boldsymbol{i}}$ indicates the $\boldsymbol{i}$ different practices ( $L T=$ Leaf Testing, $S T=$ Soil Testing, $C C=$ Cover Crops, $I N=$ Irrigation $\mathrm{N}$ Testing, $M P=$ Moisture Probe, $S A=$ Split Application, $P B=$ Pressure Bomb, $E T=$ Evapotranspiration-based scheduling) of interest and $\boldsymbol{X}_{\boldsymbol{n}}$ are the predictor variables of interest. Our unit of analysis is an individual farmer. For farmers who operate across multiple fields, we evaluate their practice adoption only on the largest field of their most important crop, thus including only one observation per farmer. This yields a matrix of estimated model coefficients, with the coefficient for each covariate $\left(\boldsymbol{B}_{1 i} \ldots \boldsymbol{B}_{n i}\right)$ estimated for each of the eight practices. The MVP assumes that the error terms for each practice $\left(\boldsymbol{e}_{L T}, \boldsymbol{e}_{S T}, \boldsymbol{e}_{C C} \ldots\right)$ jointly follow a multivariate normal distribution with a mean of 0 and variance of 1 . The model also generates a variance-covariance matrix that provides the correlation coefficients (rho) between the error terms of all pairs of equations. These correlations can offer insight on the complementary (i.e. positive correlations) or substitutable (i.e. negative correlations) nature of pairs of practices.

Simulated maximum likelihood techniques are used to estimate the model, and following Cappellari and
Jenkins (2003), our MVP models are estimated using the Geweke-Hajivassiliou-Keane (GHK) simulator in Stata 16. Multivariate normal probabilities are calculated at each iteration of the simulation. Simulation bias is minimized by increasing the number of random draws from the simulator, to at least as large as the square root of the sample size; we ran the model with 35 random draws (Cappellari and Jenkins 2003). We also tested for any ordering effects in the dependent variables by running the model with multiple different orders for the practice dependent variables; results were consistent across all runs. As an additional robustness check, we fit individual univariate probit regression models for each of the eight practices, which produces very similar coefficient estimates (See Online Appendix for additional discussion on robustness and Table A7 for univariate probit results).

To test $\mathrm{H} 1$, we evaluate the MVP variance-covariance matrix alongside a co-occurrence matrix. The co-occurrence matrix uses observed adoption data and calculates the proportion of all farmers who jointly adopt any two practices, evaluating all possible dyads of practices, a method that has been applied widely in ecology to evaluate species cooccurrence (Hines and Keil 2020). Both relatedness matrices are visualized as undirected weighted networks with the edge weights between every pair of practices reflecting the relatedness of those two practices. We use Quadratic Assignment Procedure (QAP) matrix correlation to assess which practices frequently occur together and which practices have highly correlated errors, indicating a potential underlying dimension influencing their adoption.

To test $\mathrm{H} 2$, we draw on descriptive statistical analyses including Pearson's chi-squared tests to investigate differences in individual practice adoption rates between farm types and evaluate our MVP coefficient estimates to understand the predictive power of key farm operation characteristics of interest (crop type, farm size, irrigation system and water source), while controlling for all other farmer behavior and demographic variables, as well as interdependency across practices. We then qualitatively evaluate differences in practice portfolios across different operation types by looking at differences in the co-occurrence practice networks. We highlight results for practice portfolio differences across farm types with different irrigation systems, but additional side-by-side practice portfolio comparisons between other operation types are included in the Online Appendix Figures A3-A4.

Descriptive statistics and data visualization were carried out in R Statistical Software Version 3.5.3; multivariate modelling was conducted in Stata16. All model code is linked in the Online Appendix. 


\section{Results}

Our results are structured around our hypotheses. First, to evaluate how adoption decisions are interrelated across practices (H1), we present the MVP model error correlation matrix and practice co-occurrence matrix, as well as the QAP correlation between the two measures. Then, we evaluate how farm operation characteristics influence individual practice and portfolio adoption (H2) by reviewing the MVP coefficient estimates and descriptively comparing co-occurrence networks across different farm types.

\section{Interdependence in practice adoption (H1): MVP model error correlation and co-occurrence matrices}

On average, farmers report adopting 3.5 out of eight $\mathrm{N}$ management practices. Adoption rates for individual practices ranged from $75 \%$ (split application) to $14 \%$ (pressure bomb), but the majority of all farmers adopt split application, leaf testing and soil testing (See Fig. 2).

The MVP variance-covariance correlation matrix and the practice co-occurrence matrix support $\mathrm{H} 1$, in that both measures show strong relatedness between practices and demonstrate that practices cluster most strongly within the fertilizer farm management area.
The MVP variance-covariance matrix indicates appropriate use of the MVP model, as the likelihood ratio test for the overall correlation of error terms $\left[p_{\mathrm{LT}}=p_{\mathrm{ST}}=p_{\mathrm{SA}}=p_{\mathrm{CC}}=p_{\mathrm{IN}}\right.$ $=p_{\mathrm{ET}}=\mathrm{p}_{\mathrm{PB}}=\mathrm{p}_{\mathrm{MP}}=0 ; \chi^{2}(28)=208.781$, Prob $\left.>\chi^{2}=0.000\right]$ rejects the null hypothesis that the error terms across adoption equations were not correlated. This result is also supported by the many significant correlation coefficients between the pairwise model correlation terms (see Table 2). Nearly all practices are positively correlated, and thus can be considered complementary. The fertilizer-specific practices however, emerge as the core practices that are the most frequently adopted and have the highest correlations in their error terms with each other, indicating the greatest interdependency: leaf testing and soil testing $(\rho=0.63)$, leaf testing and irrigation well $\mathrm{N}$ testing $(\rho=0.39)$, leaf testing and split application $(\rho=0.38)$.

The co-occurrence matrix further indicates that leaf testing, soil testing and split application make up the core of the portfolios for most farmers, with co-occurrence rates all at $50 \%$ or greater. Each of these three practices also cooccurred over $30 \%$ of the time with moisture probes and roughly $25-30 \%$ of the time with both irrigation well $\mathrm{N}$ testing and ET-based irrigation scheduling. Cover crops and pressure bombs were most peripheral and had the lowest cooccurrence rates with any other practice (see Online Appendix Table A8 for all co-occurrence rates). The co-occurrence

\section{Practice Adoption of All Respondents}

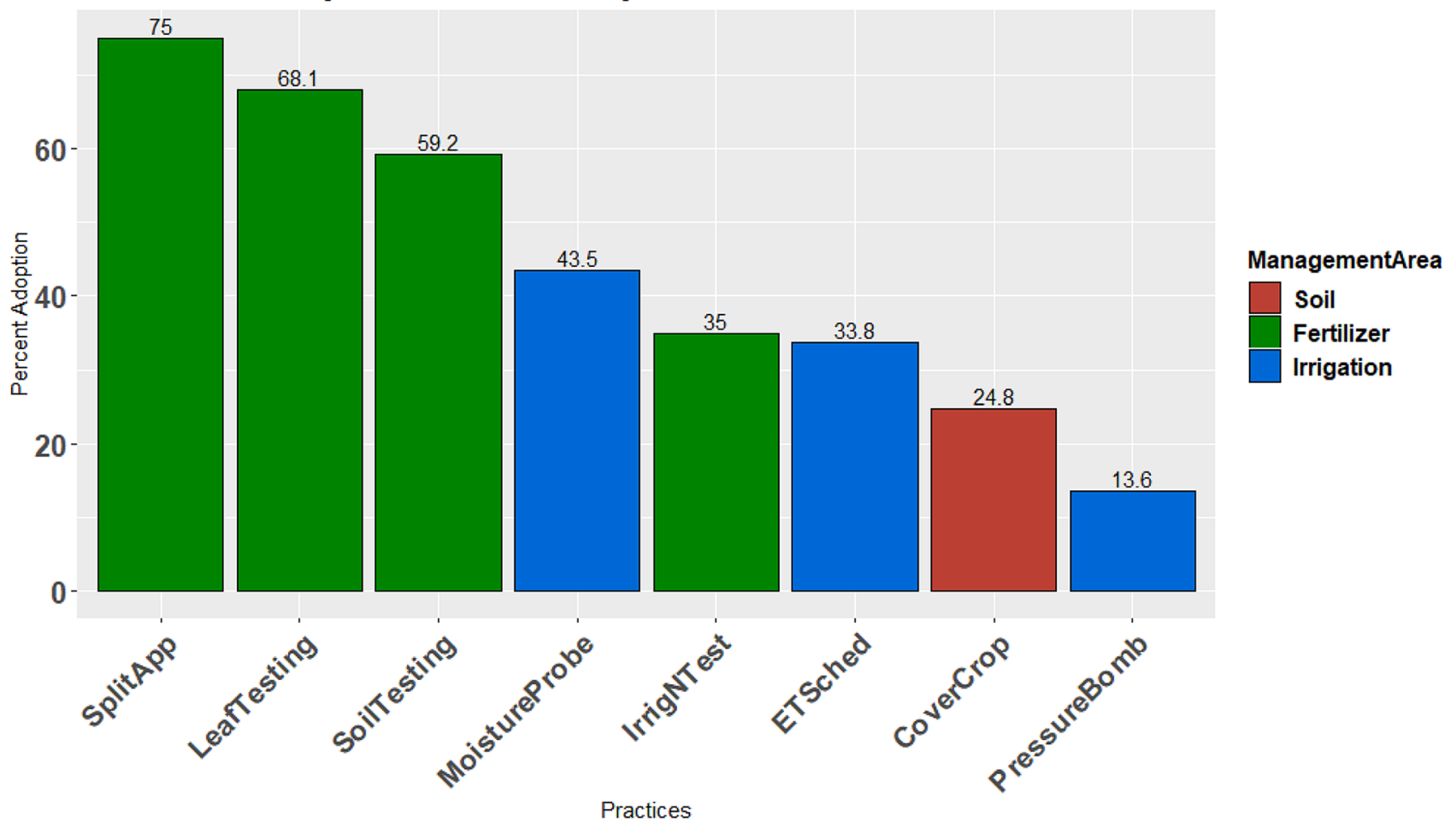

Fig. 2 Individual practice adoption rates across all farms; colors indicate management area of the farm. (Color figure online) 


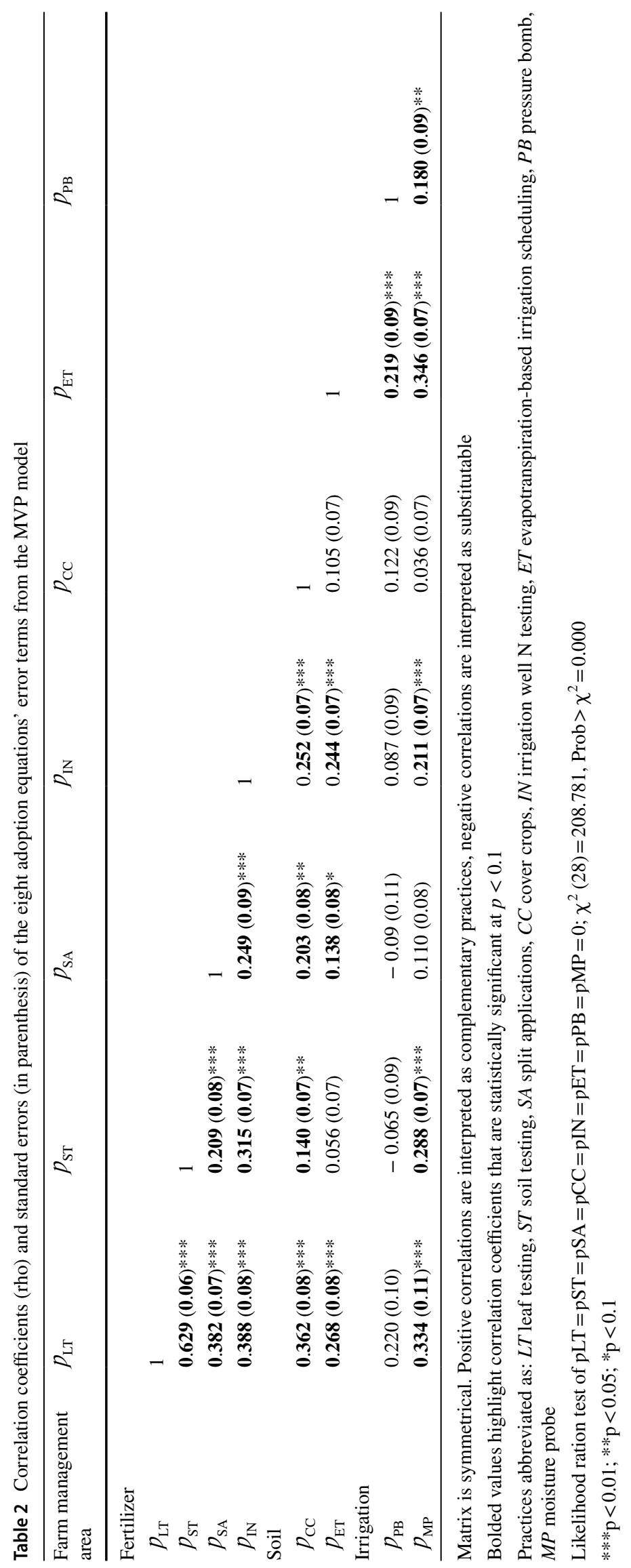




\section{Practice co-occurrence network}

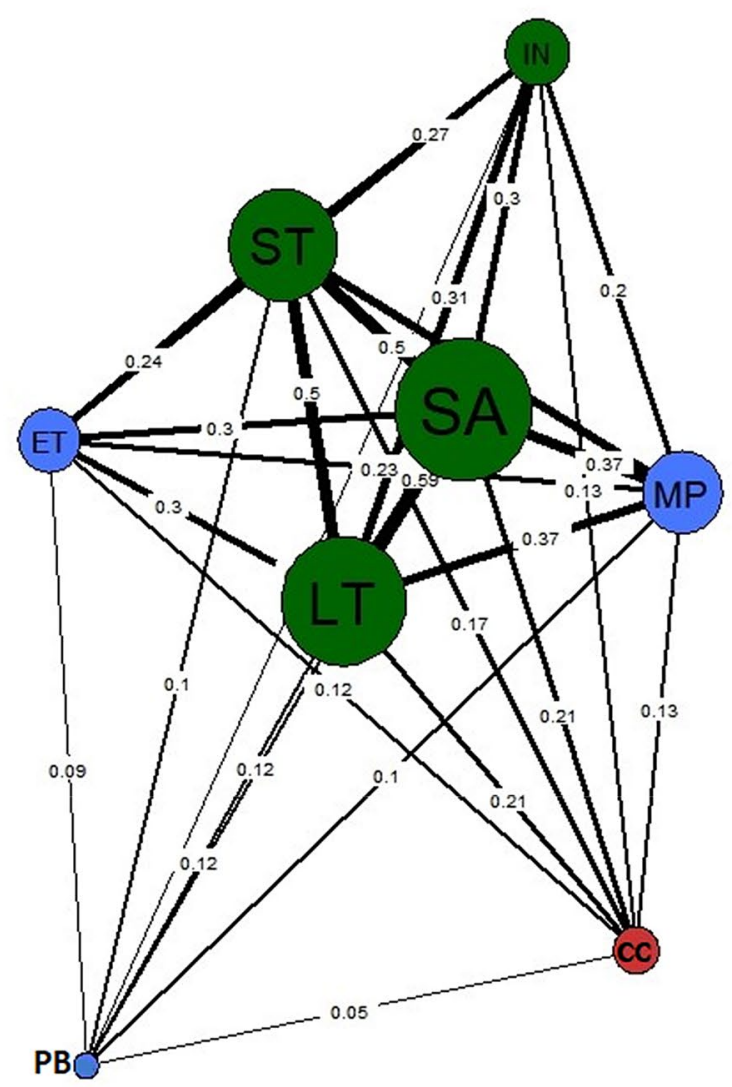

MVP Variance-Covariance Network

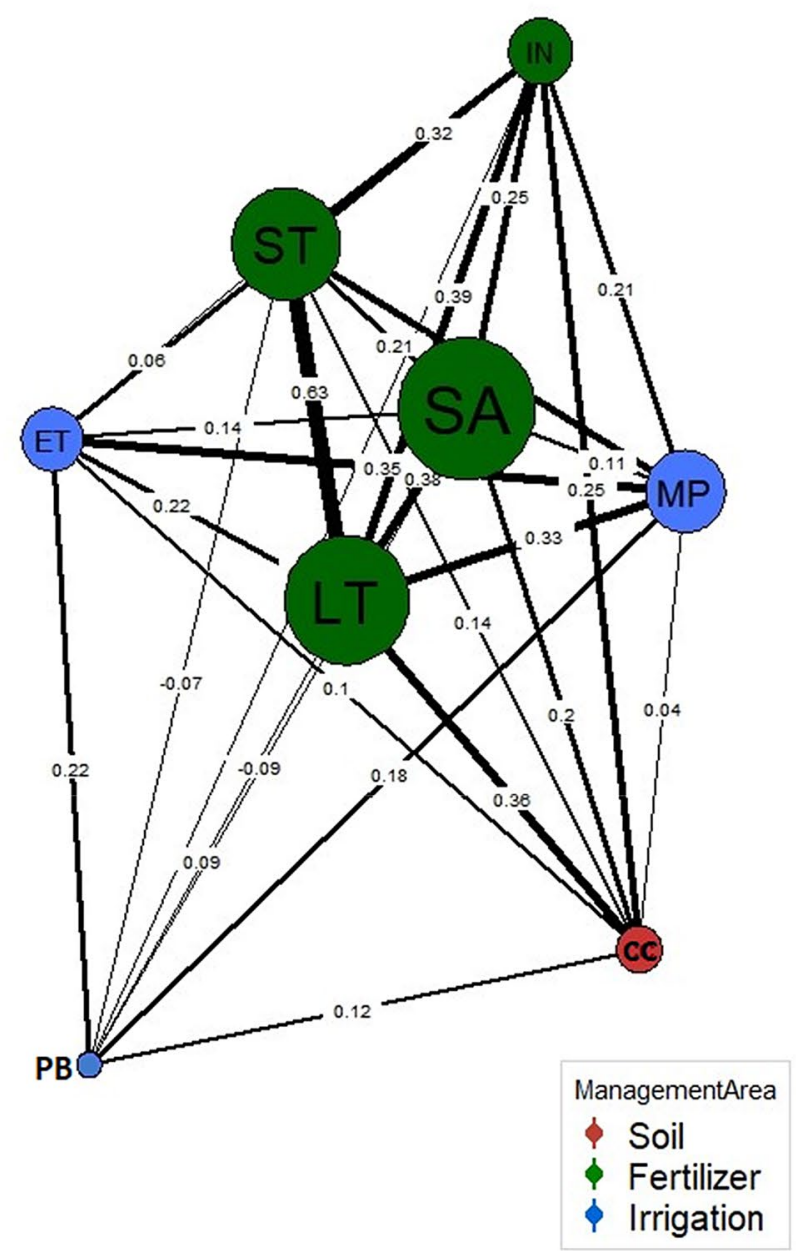

Fig. 3 Practice interdependency networks shown. Nodes represent management practices, colored based on farm management areas and scaled based on adoption rates, with larger nodes representing higher adoption. Practice names are abbreviated as: $L T$ leaf testing, $S T$ soil testing, $S A$ split applications, $C C$ cover crops, $I N$ irrigation well $\mathrm{N}$ testing, $E T$ evapotranspiration-based irrigation scheduling, $P B$ pres-

and MVP error correlations are visualized as networks with edge weights representing the strength of the relationship between two practices based on the two relatedness measures (See Fig. 3).

The Quadratic Assignment Procedure demonstrates the MVP variance-covariance and co-occurrence matrices are positively correlated and thus consistent with one another $(\mathrm{r}=0.62 ; p<0.001$; see Figure A1 in Online Appendix). The largest residuals were observed with split application when paired with other practices such as soil testing, leaf testing and moisture probe; split application has higher co-occurrence rates with each of these practices than error correlation rates in the MVP model. sure bomb, MP moisture probe. (Left) The co-occurrence network has edge weights representing the frequency at which two practices are jointly adopted on the same parcel. (Right) The MVP variance-covariance network has edge weights showing the correlation in errors between individual practice equations estimated through the MVP model

\section{Farm type influences individual practice and portfolio adoption (H2): adoption rates and MVP coefficient estimates}

In addition to evaluating the interdependency between practices, we compared how adoption of individual practices and practice portfolios differed across farm types. We find significantly higher rates of adoption for all eight practices in perennial crop systems as compared to annual crop systems $(p<0.001)$, very large farms ( $>1000$ acres $)$ as compared to smaller farms $(p<0.05)$, and operations with pressurized irrigation infrastructure as compared to gravity-fed irrigation $(p<0.05)$. Farmers with access to both surface and groundwater adopted six of the eight practices at significantly 


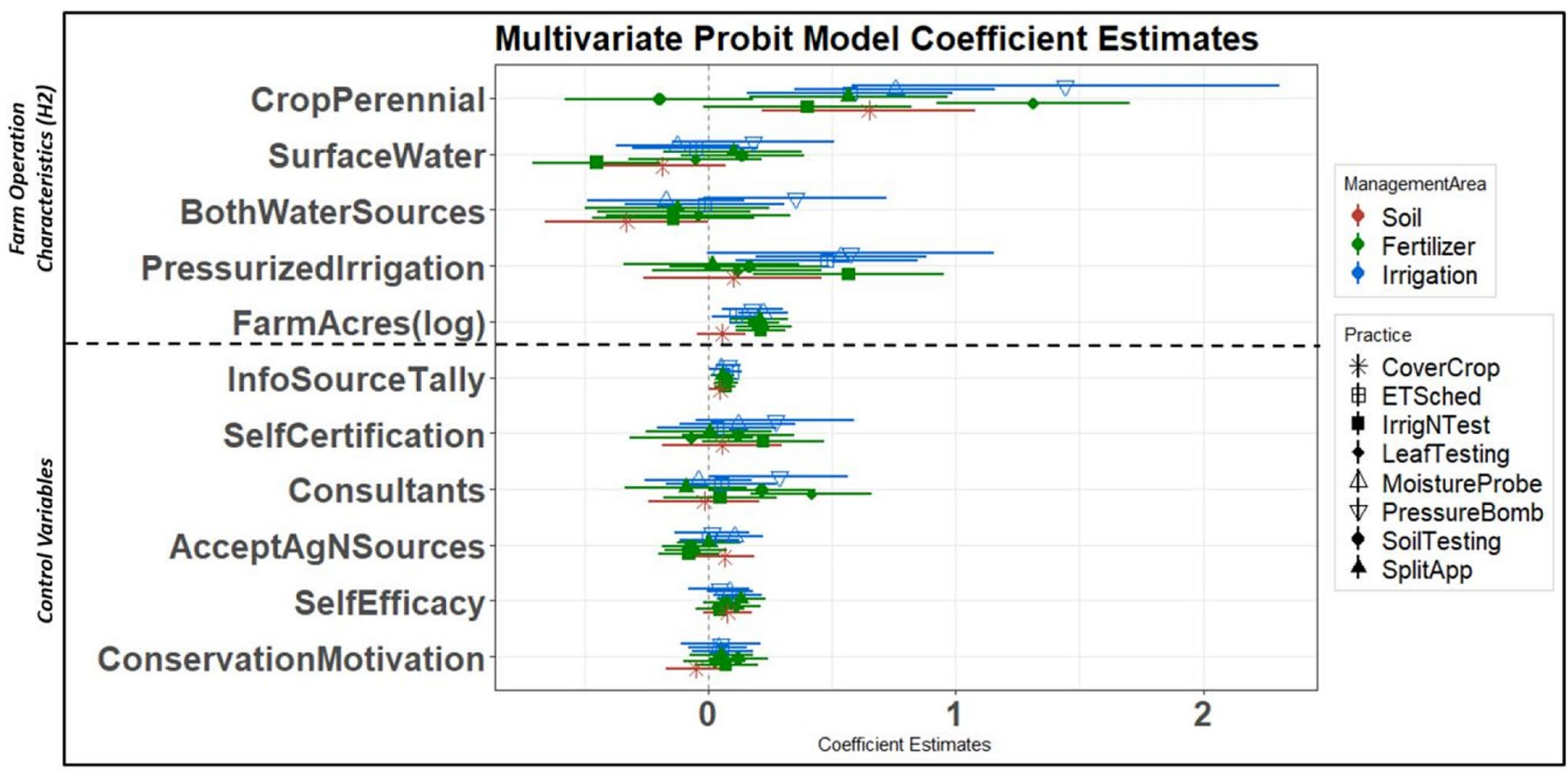

Fig. 4 MVP model coefficient estimates and 95\% confidence intervals plotted for each practice (denoted by different shape markers), with practices colored by farm management areas

higher rates $(p<0.01)$, with the exceptions of cover crops, where adoption was higher with access to groundwater only $(p<0.05)$, and soil testing, where there were no significant differences across water sources (Online Appendix Figure A2).

While adoption rates vary significantly when we look at each farm operation characteristic in isolation, our MVP results support $\mathrm{H} 2$, indicating crop type, farm size and irrigation system are the most important adoption predictors, when controlling for multiple farm operation and sociobehavioral factors. Perennial crop type is a positive and significant predictor for all practices except soil testing. Farm size is a positive and significant predictor for all practices except cover crops. Pressurized irrigation system is the farm operation characteristic that most distinguishes adoption drivers between different practices, as a positive and significant predictor for irrigation-specific practices (moisture probe, pressure bomb and ET-based irrigation scheduling), as well as irrigation well $\mathrm{N}$ testing. Water source variables however, were seldom significant predictors for any practice.

Among the information, socio-behavioral and farmer demographic control variables, information source tally was the only variable that had a positive and significant effect on all practices. The other socio-behavioral and demographic variables were less consistently significant across all practices, but generally in the direction predicted by existing literature (see Fig. 4; all model coefficients are presented in Online Appendix Table A9).
The effect of farm type is also evident when we evaluate differences in practice portfolios. Results indicate partial support for $\mathrm{H} 2$, with irrigation system being a driving factor in determining if and how farmers integrate the irrigation management practices into their $\mathrm{N}$ management portfolios. On pressurized-irrigation farms, we see greater overall cooccurrence of most practices, but more noticeably, we see an expansion of the core practices adopted by most farmers to include moisture probes, ET-based irrigation scheduling, and irrigation well $\mathrm{N}$ testing (see Fig. 5).

\section{Discussion}

Improved $\mathrm{N}$ management to maximize crop use and minimize losses to the environment is complex, requiring farmers regularly monitor, evaluate and adapt. The relevant suite of management practices needed to address these multiple dimensions stretch across different management areas of the farm and vary with other operational characteristics. Our results highlight the complexity and interdependency of farmers' adoption of these practices.

On average, California farmers adopt between three and four of the eight $\mathrm{N}$ management practices we measured. Regarding H1, we find fertilizer practices form the core of most farmers' practice portfolios, with greater practice adoption and co-occurrence rates and greater covariance in our multivariate modelling. Regarding $\mathrm{H} 2$, we find that individual practice and portfolio adoption varies across farm 


\section{Pressurized Irrigation Farms $(n=687)$}

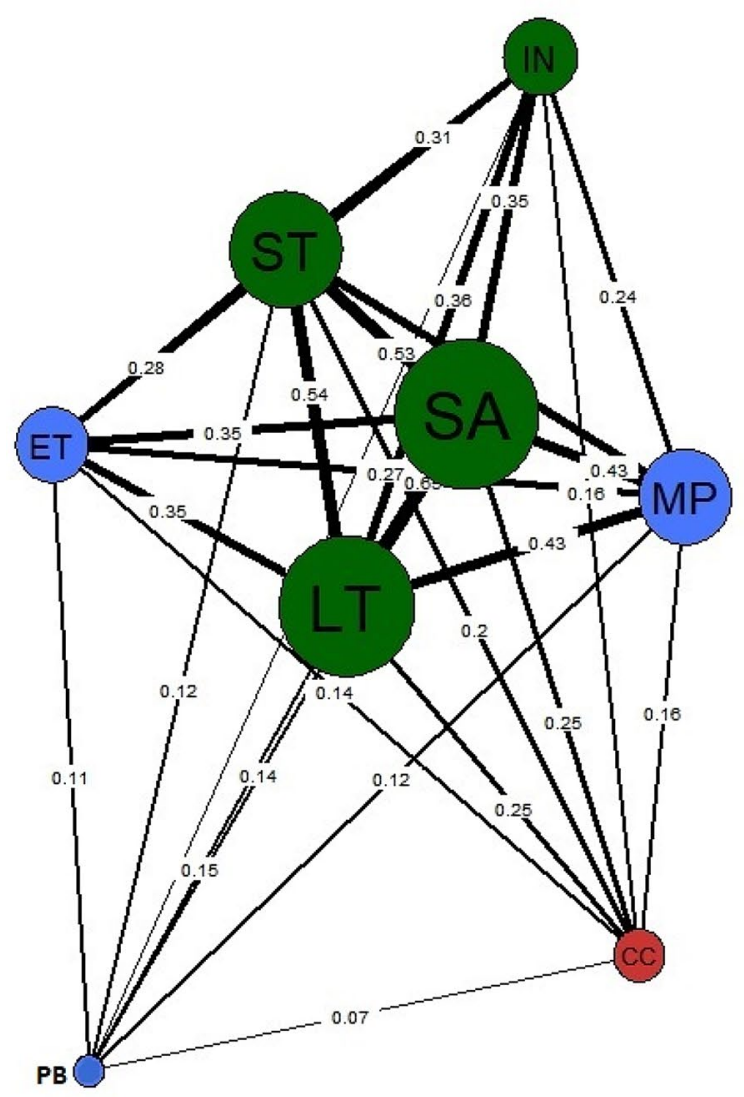

\section{Gravity-Fed Irrigation Farms ( $\mathrm{n}=186)$}

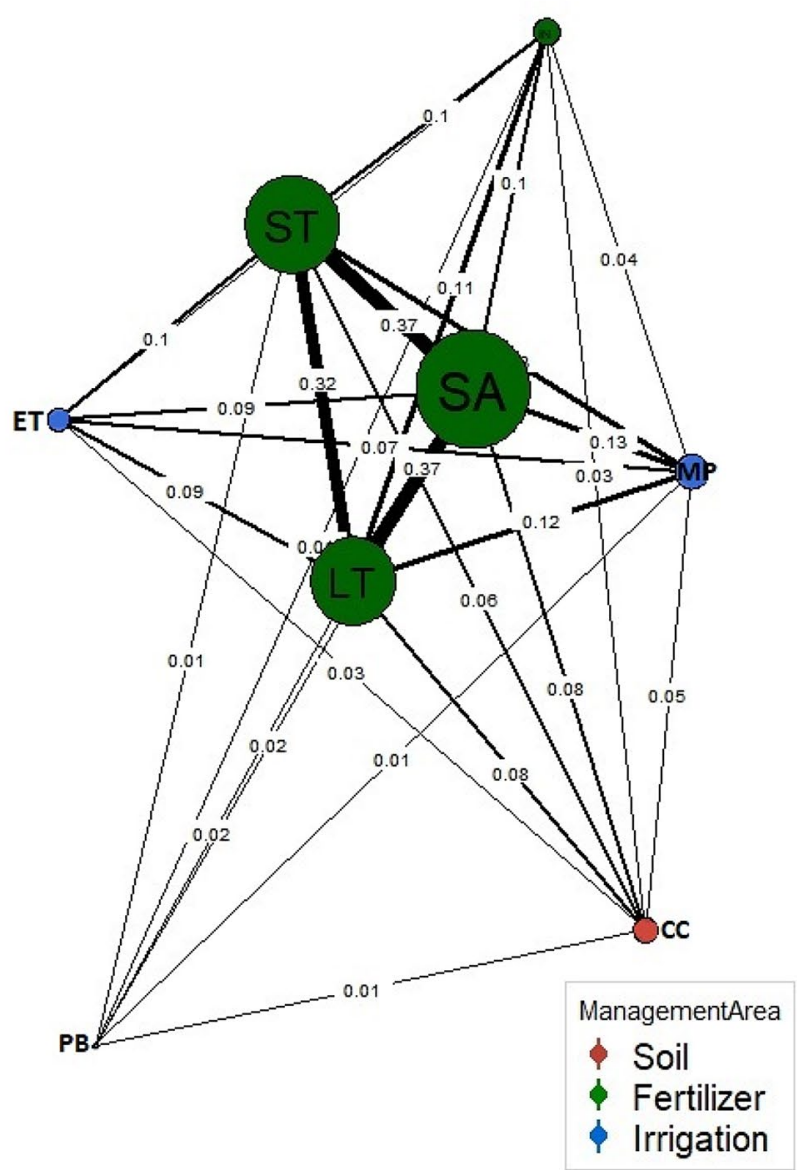

Fig. 5 Practice co-occurrence networks compared between pressurized-irrigation farms (left) and gravity-fed irrigation farms (right). Nodes represent management practices, colored based on farm management areas and scaled based on adoption rates, with larger nodes representing higher adoption. Practice names are abbreviated as: $L T$

types, with larger farms and perennial crop farms adopting more practices overall and farms with pressurized irrigation systems integrating irrigation-related practices more readily into their portfolios. Applying a farm systems conceptual and analytical approach motivates our explicit measurement of the interdependencies across multiple practices and facilitates our interpretation of how and why farmers make decisions to adopt multiple practices to fit their farm operation.

\section{Potential mechanisms driving adoption and interdependence patterns}

The survey and modelling results show strong evidence of practice interdependence and complementarities, which is consistent with multiple mechanisms that might support systems thinking. These results, combined with our leaf testing, $S T$ soil testing, $S A$ split applications, $C C$ cover crops, $I N$ irrigation well $\mathrm{N}$ testing, ET evapotranspiration-based irrigation scheduling, $P B$ pressure bomb, $M P$ moisture probe. Edge weights represent the frequency at which two practices are jointly adopted on the same parcel, for the farm operation type

interdisciplinary research team's agronomic expertise and our qualitative field work, prompt the following postulations about why fertilizer-focused practices are more readily adopted and why practice portfolios vary across farm types.

First, Cooperative Extension and on-farm technical consultants have historically emphasized fertilizer application and monitoring practices. Cooperative Extension has heavily focused on providing fertilizer application rate recommendations for different crop types (Geisseler 2016) and has promoted the $4 R$ 's framework as a decisionsupport tool for adjusting fertilizer applications. On-farm technical consultants, such as Certified Crop Advisers who can approve the $\mathrm{N}$ Management Plans required by farmers under the ILRP (if the farmer is not Self-Certified), also play a large role in disseminating practice knowledge. 
These consultants provide fertilizer product and application rate recommendations, and oftentimes carry out field and crop monitoring practices (i.e. leaf and soil testing) on behalf of the farmer. However, some of these consultants work for fertilizer companies as product representatives, which can create misaligned incentives for promoting practices that reduce fertilizer use.

Irrigation well $\mathrm{N}$ testing is noteworthy, as it has recently become part of standard fertilizer practices. In response to continuing concerns about nitrate contamination in groundwater, the State Water Board updated the ILRP mandatory reporting requirements in 2018 to require farmers to measure nitrate levels in their irrigation wells and include it as part of their N budget. The idea to "pump and apply" has thus only relatively recently become integrated into Cooperative Extension outreach efforts and CCA recommendations (Nitrogen Management Training Materials 2019). This may help to explain our observation of increasing adoption and co-occurrence rates with the traditional set of fertilizer practices. The heavy emphasis of extension and technical consulting on fertilizer-related practices overall is likely to be a key factor driving our observations of these practices being featured at the core of most farmers' practice portfolios. Furthermore, it illuminates opportunities for extension and outreach to diversify practice recommendations to increase adoption of the more peripheral irrigation and soil-focused practices.

In concordance with the statistical results, our qualitative field work suggests connections between fertilizer, soil and irrigation management are still not widely understood across technical consultant or farmer communities. Irrigation practices specifically have only been integrated into $\mathrm{N}$ management in relatively recent research and extension efforts that have expanded to consider the full farm system. Yet, in functionally differentiated farming operations (Kling and Mackie 2019), technical consultants and in-house farm managers may only specialize in one component of the farm system (e.g. fertility management) and lack expertise to integrate across fertility and irrigation. Thus, holistic practice recommendations that integrate multiple areas of the farm are still rather limited to university researchers and Cooperative Extension and a small subset of innovative farmers and technical consultants. The limited understanding of this connectivity between multiple areas of the farm and their impact on $\mathrm{N}$ management helps to explain the limited inclusion of irrigation practices and cover cropping in farmers $\mathrm{N}$ management practice portfolios.

Second, the peripheral status of irrigation management practices, exacerbated on farms with gravity fed irrigation, annual crops and smaller farm size, exemplifies how the benefits and costs of practices vary across farming contexts. The impact of access to capital- including financial, technical and social capital- is apparent across all practices, with larger farms, perennial crop farms, and farmers accessing more information sources adopting all practices at higher rates. These findings are consistent with much past adoption research that highlights the importance of economies of scale, capacity to accept risk, and social and informational networks as key factors that help to lower the barriers to adoption (Houser et al. 2019; Lubell and Fulton 2008; Marra et al. 2003; Prokopy et al. 2019).

Differences in adoption of irrigation management practices specifically, were even more apparent across farms with different irrigation infrastructure, with pressurized irrigation system farms being significantly more likely to adopt the irrigation-focused practices and integrate them into their overall $\mathrm{N}$ management portfolios. Many of the irrigation management practices require increased investment in equipment and supplies, technical learning, and time to implement. Pressurized irrigation infrastructure may be a proxy indicating an additional level of capacity for capital investment and operational sophistication.

Moreover, the ability for farms with pressurized irrigation systems to more precisely control water delivery may serve to make some of the irrigation-specific practices seem more advantageous in these systems. For example, a farmer working with a groundwater-fed, drip irrigation system has more ability to adjust their irrigation timing and total water delivered in response to evapotranspiration or moisture probe data; thus adopting these practices improves their water use efficiency. In contrast, a farmer with a flood irrigation system dependent on surface water deliveries is not able to irrigate any time they want and instead is beholden to the water district delivery schedule. Their reduced flexibility for irrigation may make the irrigation-specific practices seem obsolete. These examples are used to illustrate why the irrigation practices may be perceived to be better 'fit' in the portfolios of farms with pressurized irrigation systems. We do want to make clear however, the irrigation practices in and of themselves are not reliant on pressurized irrigation systems and could be put to use in gravity-feed irrigation systems.

\section{Limitations and future work}

As with much survey-based research, our results may be limited by low response rates, particularly in SJDWQC and ESJWQC. Further, we acknowledge the possibility of a response bias from farmers who are more engaged in extension, outreach and ILRP activities. However, our sample is a relatively good representation of the diversity of types and size of agricultural operations in California's Central Valley. Our analyses are also constrained to evaluating adoption only on farmers" "most important" parcels. This may lead to overrepresentation of perennial crop types and larger parcels in our analyses and underpredict how these same farmers manage their smaller or 
annual parcels differently. Overcoming this data limitation, while not dramatically increasing the burden placed on survey respondents, could be achieved by pairing our survey data with reporting data collected by programs like the ILRP. However, concerns about confidentiality often limit the capacity to connect data collected by researchers to data collected by other organizations, and particularly those involved in regulatory programs.

We contend that measuring and studying adoption of the interdependencies between practices is essential to moving forward on understanding drivers and barriers to adoption, and designing policy and outreach that adequately account for how interdependencies vary with practice-specific attributes (c.f. Reimer et al. 2012a). It will be helpful to characterize how the costs and benefits of practices vary with farm operation characteristics, and how they accrue when practices are used in tangent with one another, as part of the same portfolio. It is also worth noting that relevant management practices will vary across contexts. The practices considered as best practices for improving $\mathrm{N}$ management in California differ from the frequently studied practices for water quality protection in the Midwest, such as filter or buffer strips, side dressing, nitrification inhibitors, or tillage (Denny et al. 2019; Stuart et al. 2014).

It is additionally important to analyze the relationship between different portfolios of practices and agronomic and environmental outcomes. It is possible that two practices that are frequently co-adopted on a specific type of farm are actually a mal-adaptive combination when considering the goal of improved $\mathrm{N}$ use efficiency. A critical next step for agronomic research should be to develop better understandings of the agronomic, economic and environmental outcomes associated with different practice portfolios on different types of farms. This can serve as the basis for developing practice portfolio recommendations tailored to specific farm types, where the interactions between multiple practices and the constraints and opportunities of the full farm system are taken into account.

Future research should seek to further extend the farm systems approach by considering not only how $\mathrm{N}$ management practices relate to one another, but also how $\mathrm{N}$ management practices might relate to other farm management decisions, like pest management, farm investment, labor constraints, and on-farm data collection. We must consider how farmers organize their operations and management staff, the timing of management decisions on different parts of the farm, and how management practices that optimize for one outcome (e.g. $\mathrm{N}$ use efficiency) may influence other agronomic, economic or ecological outcomes. The farm systems approach is broadly applicable beyond the study of $\mathrm{N}$ management and should be incorporated into the study of other conservation practice and on-farm technology adoption. Expanding the research lens to explicitly measure the mechanisms driving interdependencies across multiple areas of the farm system may provide for greater insight to understand and predict farmer decision-making across a variety of behaviors of interest.

Finally, encouraging more holistic approaches to farm management challenges will require that the farm systems framework move beyond research in the academy and become adopted as a way of practice by extension and onfarm consultants, who provide critical technical assistance and trusted practice recommendations. This emphasizes the need for an 'Extension 3.0 model' (Lubell et al. 2014), in which university extension focus their efforts on 'training the trainer' with a farm systems approach to addressing the management challenge at hand.

\section{Conclusions}

This study contributes the most comprehensive analysis of farmer behavior on $\mathrm{N}$ management in California to date, illuminating adoption trends for a suite of practices across a wide range of farm and farmer characteristics. We analyze adoption of eight $\mathrm{N}$ management practices that stretch across fertilizer, soil and irrigation components of the farm. We argue an integrated farm systems approach improves our understanding of farmers' decision-making across different farm operation contexts and management practices, allowing us to better capture the complexity and interdependency of adoption decision-making on portfolios of practices. Our findings highlight how adoption patterns and adoption drivers differ across practices, and how the combination or portfolio of practices adopted may differ quite dramatically across heterogeneous farms, based on operational characteristics that influence fit.

Our interdisciplinary and engaged approach further informs the outreach and policy recommendations that follow from our results. We have observed that the large heterogeneity in California's farms result in neighboring operations facing dramatically different barriers or achieving greatly different benefits with the adoption of an individual practice or specific portfolio of practices. The "disproportionality" of impact (Nowak et al. 2006) on N pollution means that motivating and focusing extension efforts to increase adoption on large, input-intensive operations increases the likelihood of achieving sustainability goals. Yet, we see that large size and greater capital are important enabling factors increasing likelihood of adoption already, and these operations may be able to achieve higher private returns due to increased efficiency or other co-benefits. In contrast, small farms with smaller individual $\mathrm{N}$ footprints, may face extreme financial, technical or information barriers to implement even the easiest practices. These factors must be considered in justifying and tailoring financial incentive and technical assistance 
programs that are aimed to increase and maintain practice adoption. Our results suggest that $\mathrm{N}$ management extension and technical assistance programs in California should focus on developing practice portfolio recommendations that are adapted to fit small farms, annual cropping systems and operations that don't currently have pressurized irrigation infrastructure in place.

Furthermore, a novel opportunity exists in California to coordinate policy and extension to promote a holistic approach to $\mathrm{N}$ management through the implementation of the ILRP. As our survey results and field work have illuminated, $\mathrm{N}$ management policy and extension efforts have historically focused on fertilizer practices, resulting in greater adoption and integration of these practices, at the expense of holistic portfolios that integrate soil and irrigation practices as well. Developing practice portfolio recommendations that integrate irrigation, soil and fertilizer practices together, and are tailored to different types of farms should be a priority for $\mathrm{N}$ management research and extension going forward. The effort to develop tailored portfolio recommendations could also clarify how to measure improvement around $\mathrm{N}$ management, since using all, or more management practices may not always be applicable or optimal for all operations. Evaluating whether farmers are adopting the best-suited portfolio of practices for their specific farm context may provide a more tangible goal for farmers, while also providing more clarity to the public and policymakers as to when and how reductions in $\mathrm{N}$ pollution may be reached.

We suggest a coordinated approach engaging all of the key actors across the wide information and extension network working on this issue: California Department of Food and Agriculture, State and Regional Water Boards, Water Quality Coalitions, USDA Natural Resources Conservation Service, Resource Conservation Districts, commodity groups, University of California Cooperative Extension, on-farm PCAs and CCAs, NGOs and private sector companies. Combined, this network of actors has the resources, reach, and earned trust of farmers to develop comprehensive strategies that seek to (1) diversify and incorporate practices across the entire farm that holistically address $\mathrm{N}$ management, (2) shift social norms away from excess fertilizer application as 'cheap yield insurance', and (3) provide creative incentives through shared risk approaches, technical assistance in implementation and maintenance, market recognition and reduced regulatory burdens. Together these efforts can promote and sustain a farm systems approach to $\mathrm{N}$ management.

Supplementary Information The online version contains supplementary material available at https://doi.org/10.1007/s10460-021-10190-5.

Acknowledgements We would like to acknowledge all farmers who voluntarily participated in our survey, the Water Quality Coalitions who facilitated our study and ensured relevancy of this work, and the many members of our Survey Advisory Committee who gave ample feedback throughout the project and continuously work to support progress on nitrogen management in the field; this work would not be possible without all of their support. We also acknowledge and appreciate that this work was funded by a competitive grant from the California Department of Food and Agriculture Fertilizer Research and Education Program.

Funding Funding was provided by California Department of Food and Agriculture Fertilizer Research and Education Program (Grant No. 16-0620).

Open Access This article is licensed under a Creative Commons Attribution 4.0 International License, which permits use, sharing, adaptation, distribution and reproduction in any medium or format, as long as you give appropriate credit to the original author(s) and the source, provide a link to the Creative Commons licence, and indicate if changes were made. The images or other third party material in this article are included in the article's Creative Commons licence, unless indicated otherwise in a credit line to the material. If material is not included in the article's Creative Commons licence and your intended use is not permitted by statutory regulation or exceeds the permitted use, you will need to obtain permission directly from the copyright holder. To view a copy of this licence, visit http://creativecommons.org/licenses/by/4.0/.

\section{References}

Ajzen, I. 1989. The Theory of Planned Behavior. Organizational Behavior and Human Decision Processes 50: 179-211.

American Association for Public Opinion Research. 2016. Response Rate Calculator V4.0. 2016. http://www.aapor.org/EducationResources/For-Researchers.aspx.

Arbuckle, J. G., and Hanna Rosman. 2014. Iowa Farmers' Nitrogen Management Practices and Perspectives. http://lib.dr.iasta te.edu/extension_communities_pubs/24.

Aubert, B.A., S. Andreas, and J. Grimaudo. 2012. IT as Enabler of Sustainable Farming: An Empirical Analysis of Farmers' Adoption Decision of Precision Agriculture Technology. Decision Support Systems 54 (1): 510-520. https://doi.org/10.1016/j. dss.2012.07.002.

Baumgart-Getz, A., L.S. Prokopy, and K. Floress. 2012. Why Farmers Adopt Best Management Practice in the United States: A Meta-Analysis of the Adoption Literature. Journal of Environmental Management 96 (1): 17-25. https://doi.org/10.1016/j. jenvman.2011.10.006.

Bawden, R. 1995. On the Systems Dimension in Farm Systems Research. Journal of Farm Systems Resource Extension 5 (2): $1-18$.

Blank, S. 2001. Producers Get Squeezed up the Farming Food Chain: A Theory of Crop Portfolio Composition and Land Use. Applied Economic Perspectives and Policy 23 (2): 404-422.

Bosch, N.S., J.D. Allan, J.P. Selegean, and D. Scavia. 2013. ScenarioTesting of Agricultural Best Management Practices in Lake Erie Watersheds. Journal of Great Lakes Research 39 (3): 429-436.

California Department of Food and Agriculture. 2018. California Agricultural Statistics Review 2017-2018. Sacramento, CA. https://www.cdfa.ca.gov/statistics/PDFs/2017-18AgReport.pdf.

Cappellari, L., and S.P. Jenkins. 2003. Multivariate Probit Regression Using Simulated Maximum Likelihood. The Stata Journal: Promoting Communications on Statistics and Stata 3 (3): 278-294. https://doi.org/10.1177/1536867x0300300305.

Central Valley Regional Water Quality Control Board. 2020. Irrigated Lands Regulatory Program (ILRP) Frequently Asked 
Questions. https://www.waterboards.ca.gov/centralvalley/water _issues/irrigated_lands/ilrp_faq.pdf.

Church, S.P., J. Lu, P. Ranjan, A.P. Reimer, and L.S. Prokopy. 2020. The Role of Systems Thinking in Cover Crop Adoption: Implications for Conservation Communication. Land Use Policy 94: 104508.

Coates, R.W., M.J. Delwiche, and P.H. Brown. 2005. Precision Irrigation and Fertilization in Orchards. In ASAE Annual Meeting. American Society of Agricultural and Biological Engineers. https://doi.org/10.13031/2013.19815

Conley, T., and C. Udry. 2010. Learning about a New Technology: Pineapple in Ghana. American Economic Review 100 (1): 35-69.

Costello, A.B., and J.W. Osborne. 2005. Best Practices in Exploratory Factor Analysis: Four Recommendations for Getting the Most from Your Analysis. Practical Assessment, Research and Evaluation 10: 7.

Denny, R.C.H., S.T. Marquart-Pyatt, and M. Houser. 2019. Understanding the Past and Present and Predicting the Future: Farmers' Use of Multiple Nutrient Best Management Practices in the Upper Midwest. Society and Natural Resources 32 (7): 807-826. https://doi.org/10.1080/08941920.2019.1574045.

DeVellis, R.F. 2003. Scale Development: Theory and Applications, 2nd ed. Thousand Oaks: Sage Publications.

Dillman, D.A., G. Phelps, R. Tortora, K. Swift, J. Kohrell, J. Berck, and B.L. Messer. 2008. Response Rate and Measurement Differences in Mixed Mode Surveys Using Mail, Telephone, Interactive Voice Response and the Internet. Social Science Research 38 (1): 1-18.

Feder, G. 1982. Adoption of Interrelated Agricultural Innovations: Complementarity and the Impacts of Risk, Scale, and Credit. American Journal of Agricultural Economics 64 (1): 94-101. https://doi.org/10.2307/1241177.

Feder, G., and D. Umali. 1993. The Adoption of Agricultural Innovations: A Review. Technological Forecasting and Social Change 43 (3-4): 215-239.

Fernández, V., and P.H. Brown. 2013. From Plant Surface to Plant Metabolism: The Uncertain Fate of Foliar-Applied Nutrients. Frontiers in Plant Science 4: 289.

Fresco, L.O., and E. Westphal. 1988. A hierarchical Classification of Farm Systems. Experimental Agriculture 24 (4): 399-419.

Geisseler, D. 2016. Nitrogen Concentrations in Harvested Plant PartsA literature overview. University of California Davis. http://groun dwaternitrate.ucdavis.edu/files/269138.pdf.

Ghadim, A.K., D.J. Pannell, and M.P. Burton. 2005. Risk, Uncertainty, and Learning in Adoption of a Crop Innovation. Agricultural Economics 33 (1): 1-9. https://doi.org/10.111 1/j.1574-0862.2005.00433.x.

Giller, K. 2013. Can We Define the Term 'Farming Systems'? A Question of Scale. SAGE Journals: Outlook on Agriculture 42 (3): 149-153. https://doi.org/10.5367/oa.2013.0139.

Good, A.G., and P.H. Beatty. 2011. Fertilizing Nature: A Tragedy of Excess in the Commons. PLoS Biology 9 (8): 1-9. https://doi. org/10.1371/journal.pbio.1001124.

Halbrendt, J., S.A. Gray, S. Crow, T. Radovich, A. Kimura, and B.B. Tamang. 2014. Differences in Farmer and Expert Beliefs and the Perceived Impacts of Conservation Agriculture. Global Environmental Change 28: 50-62.

Hanson, B., D. May, J. Simnek, J. Hopmans, and R. Hutmacher. 2009. Drip Irrigation Provides the Salinity Control Needed for Profitable Irrigation of Tomatoes in the San Joaquin Valley. California Agriculture 63 (3): 131-136.

Harter, T., J.R. Lund, J. Darby, G. Fogg, R. Howitt, K. Jessoe, S. Pettygrove, J. Quinn, and J. Viers. 2012. Addressing Nitrate in California's Drinking Water: With a Focus on Tulare Lake Basin and
Salinas Valley Groundwater. Report for the California State Water Resources Control Board Report to the Legislature.

Hillis, V., M. Lubell, and M. Hoffman. 2018. Sustainability Partnership and Viticulture Management in California. Journal of Environmental Management 217: 214-225. https://doi.org/10.1016/j. jenvman.2018.03.033.

Hines, J., and P. Keil. 2020. Common Competitors and Rare Friends. Nature Ecology and Evolution 4 (1): 8-9. https://doi.org/10.1038/ s41559-019-1071-3.

Hoffman, M., M. Lubell, and V. Hillis. 2014. Linking Knowledge and Action Through Mental Models of Sustainable Agriculture. Proceedings of the National Academies of Science 111: 13016-13021.

Houser, M., S.T. Marquart-Pyatt, R.C.H. Denny, A. Reimer, and D. Stuart. 2019. Farmers, Information, and Nutrient Management in the US Midwest. Journal of Soil and Water Conservation 74 (3): 269-280. https://doi.org/10.2489/jswc.74.3.269.

Howitt, R., D. MacEwan, and J. Medellin-Azuara. 2008. Calculating California Cropping Patterns in 2050. Davis. https://water .ca.gov/LegacyFiles/waterplan/docs/cwpu2009/0310final/v4c03 a02_cwp2009.pdf.

Jara-Rojas, R., B.E. Bravo-Ureta, A. Engler, and J. Diaz. 2013. An Analysis of the Joint Adoption of Water Conservation and Soil Conservation in Central Chile. Land Use Policy 32: 292-301.

Kanter, D.R., W. Winiwarter, B.L. Bodirsky, L. Bouwman, E. Boyer, S. Buckle, J.E. Compton, T. Dalgaard, W. de Vries, D. Leclère, and A. Leip. 2020. A Framework for Nitrogen Futures in the Shared Socioeconomic Pathways. Global Environmental Change 61: 102029. https://doi.org/10.1016/j.gloenvcha.2019.102029.

Kara, E., M. Ribaudo, and R.C. Johansson. 2008. On How Environmental Stringency Influences Adoption of Best Management Practices in Agriculture. Journal of Environmental Management 88 (4): 1530-1537. https://doi.org/10.1016/j.jenvman.2007.07.029.

Kassie, M., H. Teklewold, M. Jaleta, P. Marenya, and O. Erenstein. 2015. Understanding the Adoption of a Portfolio of Sustainable Intensification Practices in Eastern and Southern Africa. Land Use Policy 42: 400-411. https://doi.org/10.1016/j.landusepol .2014.08.016.

Khalsa, S.D.S., and P.H. Brown. 2017. Grower Analysis of Organic Matter Amendments in California Orchards. Journal of Environmental Quality 46 (3): 649-658. https://doi.org/10.2134/ jeq2016.11.0456.

Khalsa, S.D.S., and P.H. Brown. 2019. Understanding Nitrogen Cycling in an Irrigated Deciduous Permanent Crop. Acta Horticultare 1253: 207-212.

Khalsa, S.D.S., T. Hartz, and P.H. Brown. 2018. Principles of Nitrogen Cycling and Management. University of California Agriculture and Natural Resources. https://ucanr.edu/sites/StrategicI nitiatives/files/301168.pdf.

Kipling, R.P., H.E. Taft, D.R. Chadwick, D. Styles, and J. Moorby. 2019. Challenges to Implementing Greenhouse Gas Mitigation Measures in Livestock Agriculture: A Conceptual Framework for Policymakers. Environmental Science and Policy 92: 107115. https://doi.org/10.1016/j.envsci.2018.11.013.

Kling, C., and C. Mackie. 2019. Improving Data Collection and Measurement of Complex Farms. Washington: National Academies of Sciences, Engineering, and Medicine. National Academies Press.

Knowler, D., and B. Bradshaw. 2007. Farmers' Adoption of Conservation Agriculture: A Review and Synthesis of Recent Research. Food Policy 32 (1): 25-48. https://doi.org/10.1016/j.foodp ol.2006.01.003.

Koppmair, S., M. Kassie, and M. Qaim. 2017. The Influence of Farm Input Subsidies on the Adoption of Natural Resource Management Technologies. Australian Journal of Agricultural and Resource Economics 61 (4): 539-556. https://doi.org/10.1111/14678489.12220 . 
Letey, J., and P. Vaughan. 2013. Soil Type, Crop and Irrigation Technique Affect Nitrogen Leaching to Groundwater. California Agriculture 67 (4): 231-241.

Levy, M.A., M.N. Lubell, and N. McRoberts. 2018. The Structure of Mental Models of Sustainable Agriculture. Nature Sustainability 1 (8): 413-420.

Liu, T., R.J.F. Bruins, and M.T. Heberling. 2018. Factors Influencing Farmers' Adoption of Best Management Practices: A Review and Synthesis. Sustainability (Switzerland) 10 (2): 1-26. https://doi. org/10.3390/su10020432.

Lopus, S.E., M.P. Santibáñez, R.H. Beede, R.A. Duncan, J. Edstrom, F.J.A. Niederholzer, C.J. Trexler, and P.H. Brown. 2010. Survey Examines the Adoption of Perceived Best Management Practices for Almond Nutrition. California Agriculture 64 (3): 149-154. https://doi.org/10.3733/ca.v064n03p149.

Lubell, M., and A. Fulton. 2008. Local Diffusion Networks Act as Pathways to Sustainable Agriculture in the Sacramento River Valley. California Agriculture 61: 131-137. https://doi.org/10.3733/ ca.v061n03p131.

Lubell, M., M. Niles, and M. Hoffman. 2014. Extension 3.0: Managing Agricultural Knowledge Systems in the Network Age. Society and Natural Resources 27 (10): 1089-1103. https://doi. org/10.1080/08941920.2014.933496.

Marra, M., D.J. Pannell, and A.A. Ghadim. 2003. The Economics of Risk, Uncertainty and Learning in the Adoption of New Agricultural Technologies: Where Are We on the Learning Curve? Agricultural Systems 75 (2-3): 215-234. https://doi.org/10.1016/ S0308-521X(02)00066-5.

McAllister, R.R.J., D. Smith, C.J. Stokes, and F.J. Walsh. 2009. Patterns of Accessing Variable Resources Across Time and Space: Desert Plants, Animals and People. Journal of Arid Environments 73 (3): 338-346. https://doi.org/10.1016/j.jaridenv.2008.10.007.

McIver, J., and E.G. Carmines. 1981. Unidimensional Scaling, vol. 24. Newbury Park, CA: Sage University Paper Series on Quantiative Applications in Social Science.

McLellan, E.L., K.G. Cassman, A.J. Eagle, P.B. Woodbury, S. Sela, C. Tonitto, R.D. Marjerison, and H.M. Van Es. 2018. The Nitrogen Balancing Act: Tracking the Environmental Performance of Food Production. BioScience 68 (3): 194-203. https://doi.org/10.1093/ biosci/bix 164

Mikkelsen, R. 2011. The '4R' Nutrient Stewardship Framework for Horticulture. HortTechnology 21 (6): 658-662.

Murendo, C., S. Gwara, N. Mpofu, T. Pedzisa, and P. Chivenge. 2016. The Adoption of a Portfolio of Sustainable Agricultural Practices by Smallholder Farmers in Zimbabwe. In 5th International Conference of the African Association of Agricultural Economists. Addis Ababa, Ethiopia.

Nitrogen Management Training Materials. 2019. California Institute for Water Resources, University of California Division of Agriculture and Natural Resources. http://ciwr.ucanr.edu/NitrogenMa nagement/.

Norman, D.W. 1980. The Farming Systems Approach: Relevancy for the Small Farmer. East Lansing, Michigan: Michigan State University.

Nowak, P., S. Bowen, and P.E. Cabot. 2006. Disproportionality as a Framework for Linking Social and Biophysical Systems. Society and Natural Resources 19 (2): 153-173.

Osmond, D.L., D.L.K. Hoag, A.E. Luloff, D.W. Meals, and K. Neas. 2015. Farmers' Use of Nutrient Management: Lessons from Watershed Case Studies. Journal of Environment Quality 44 (2): 382. https://doi.org/10.2134/jeq2014.02.0091.

Pannell, D.J., G.R. Marshall, N. Barr, and A. Curtis. 2006. Adoption of Conservation Practices by Rural Landholders. Australian Journal of Experimental Agriculture, 2001: 1407-1424. https://doi. org/10.1071/EA05037.
Prokopy, L.S., K. Floress, D. Klotthor-Weinkauf, and A. BaumgartGetz. 2008. Determinants of Agricultural Best Management Practice Adoption: Evidence from the Literature. Journal of Soil and Water Conservation 63 (5): 300-311. https://doi.org/10.2489/ jswc.63.5.300.

Prokopy, L.S., K. Floress, J.G. Arbuckle, S.P. Church, F.R. Eanes, Y. Gao, B.M. Gramig, P. Ranjan, and A.S. Singh. 2019. Adoption of Agricultural Conservation Practices in the United States: Evidence from 35 Years of Quantitative Literature. Journal of Soil and Water Conservation 74 (5): 520-534. https://doi.org/10.2489/ jswc.74.5.520.

Ranjan, P., S.P. Church, K. Floress, and L.S. Prokopy. 2019. Synthesizing Conservation Motivations and Barriers: What Have We Learned from Qualitative Studies of Farmers' Behaviors in the United States? Society and Natural Resources 32 (11): 11711199. https://doi.org/10.1080/08941920.2019.1648710.

Reimer, A.P., D.K. Weinkauf, and L.S. Prokopy. 2012a. The Influence of Perceptions of Practice Characteristics: An Examination of Agricultural Best Management Practice Adoption in Two Indiana Watersheds. Journal of Rural Studies 28 (1): 118-128.

Reimer, A., A.W. Thompson, and L.S. Prokopy. 2012b. The MultiDimensional Nature of Environmental Attitudes among Farmers in Indiana: Implications for Conservation Adoption. Agriculture and Human Values 29 (1): 29-40. https://doi.org/10.1007/s1046 0-011-9308-z.

Reimer, A., J.E. Doll, B. Basso, S.T. Marquart-Pyatt, G.P. Robertson, D. Stuart, and J. Zhao. 2017. Moving Toward Sustainable Farming Systems: Insights from Private and Public Sector Dialogues on Nitrogen Management. Journal of Soil and Water Conservation 72 (1): 5A-9A. https://doi.org/10.2489/jswc.72.1.5A.

Reimer, A., R. Denny, and D. Stuart. 2018. The Impact of Federal and State Conservation Programs on Farmer Nitrogen Management. Environmental Management 62 (4): 694-708. https://doi. org/10.1007/s00267-018-1083-9.

Rogers, E.M. 2003. Diffusion of Innovations, 5th ed. New York: Simon and Schuster.

Santos, J.R.A. 1999. Cronbach's Alpha: A Tool for Assessing the Reliability of Scales. Journal of Extension 37 (2): 1-5.

Schellenberg, D.L., R.D. Morse, and G.E. Welbaum. 2009. Organic Broccoli Production on Transition Soils: Comparing Cover Crops, Tillage and Sidedress. Renewable Agriculture and Food Systems 24 (2): 85-91.

Shaffer, S. 2013. Encouraging California Specialty Crop Growers to Adopt Environmentally Beneficial Management Practices for Efficient Irrigation and Nutrient Management.

Shaner, W., P. Philipp, and W.R. Schmehl. 1982. Farming Systems Research and Development. Boulder, CO: Westview Press.

Shaner, W., P. Philipp, and W.R. Schmehl. 2019. Farming Systems Research and Development: Guidelines for Developing Countries. New York: Routledge. ISBN: 12:978-0-367-01930-3.

Snapp, S., and B. Pound. 2008. Agricultural Systems: Agroecology and Rural Innovation for Development. Burlington, MA: Academic Press.

Snyder, C.S. 2017. Enhanced Nitrogen Fertiliser Technologies Support the '4R' Concept to Optimise Crop Production and Minimise Environmental Losses. Soil Research 55 (6): 463-472.

Stuart, D., R.L. Schewe, and M. McDermott. 2014. Reducing Nitrogen Fertilizer Application as a Climate Change Mitigation Strategy: Understanding Farmer Decision-Making and Potential Barriers to Change in the US. Land Use Policy. https://doi.org/10.1016/j. landusepol.2013.08.011.

Taylor, R., and D. Zilberman. 2017. Diffusion of Drip Irrigation: The Case of California. Applied Economic Perspectives and Policy 39 (1): 16-40. https://doi.org/10.1093/aepp/ppw026.

Teklewold, H., M. Kassie, and B. Shiferaw. 2013. Adoption of Multiple Sustainable Agricultural Practices in Rural Ethiopia. 
Journal of Agricultural Economics 64 (3): 597-623. https://doi. org/10.1111/1477-9552.12011.

Teshager, A.D., P.W. Gassman, S. Secchi, and J.T. Schoof. 2017. Simulation of Targeted Pollutant-Mitigation-Strategies to Reduce Nitrate and Sediment Hotspots in Agricultural Watershed. Science of the Total Environment 607: 1188-1200.

Tomich, T., S. Bordt, R. Dahlgren, and K. Scow. 2016. The California Nitrogen Assessment: Challenges and Solutions for People, Agriculture and the Environment. Oakland, CA: University of California Press.

Tucker, M., and T.L. Napier. 2002. Preferred Sources and Channels of Soil and Water Conservation Information among Farmers in Three Midwestern US Watersheds. Agriculture, Ecosystems \& Environment 92 (2-3): 297-313.

Ulrich-Schad, J.D., S.G. de Jalon, N. Babin, A. Pape, and L.S. Prokopy. 2017. Measuring and Understanding Agricultural Producers' Adoption of Nutrient Best Management Practices. Journal of Soil and Water Conservation 72(5): 506-518.

United States Department of Agriculture. 2018. "USDA Organic INTEGRITY Database." https://organic.ams.usda.gov/integrity/.

United States Environmental Protection Agency. 2017. Nonpoint Source: Agriculture. https://www.epa.gov/nps/nonpoint-sourc e-agriculture.

USDA Midwest Climate Hub. 2017. Agriculture in the Midwest. U.S. Department of Agriculture. 2017. https://www.climatehubs.usda. gov/hubs/midwest/topic/agriculture-midwest.

van Rooyen, J. 1984. Agricultural Economic Research in Less Developed Countries: A Farm Systems Approach. Development Southern Africa 1 (1): 56-64. https://doi.org/10.1080/0376835840 8439069.

Wauters, E., and E. Mathijs. 2014. The Adoption of Farm Level Soil Conservation Practices in Developed Countries: A Meta-Analytic Review. International Journal of Agricultural Resources, Governance and Ecology 10 (1): 78-102. https://doi.org/10.1504/IJARG E.2014.061058.

Wilson, R.S., G. Howard, and E.A. Burnett. 2014. Improving Nutrient Management Practices in Agriculture: The Role of Risk-Based Beliefs in Understanding Farmers' Attitudes toward Taking Additional Action. Water Resources Research 50: 6735-6746. https:// doi.org/10.1002/2013WR015200.Received.

Zheng, C., Y. Jiang, C. Chen, Y. Sun, J. Feng, A. Deng, Z. Song, and W. Zhang. 2014. The Impacts of Conservation Agriculture on Crop Yield in China Depend on Specific Practices, Crops and Cropping Regions. Crop Journal 2 (5): 289-296. https://doi.org/10.1016/j. cj.2014.06.006.

Zulfiqar, F., R. Ullah, M. Abid, and A. Hussain. 2016. Cotton Production under Risk: A Simultaneous Adoption of Risk Coping Tools. Natural Hazards 84 (2): 959-974. https://doi.org/10.1007/s1106 9-016-2468-9.
Publisher's Note Springer Nature remains neutral with regard to jurisdictional claims in published maps and institutional affiliations.

Jessica Rudnick is an Extension Specialist with California Sea Grant, focused on human decision-making and governance in the SacramentoSan Joaquin Delta. Dr. Rudnick completed her PhD in 2020 at UC Davis in the Center for Environmental Policy and Behavior where her research focused on farmer decision-making and agricultural governance.

Mark Lubell is a Professor of Environmental Science and Policy at UC Davis. He is the director of the Center for Environmental Policy and Behavior, where his research focuses on cooperation and decisionmaking in the context of agricultural and environmental policy.

Sat Darshan S. Khalsa is an Assistant Project Scientist in the Department of Plant Sciences at UC Davis. His research focuses on nitrogen cycling and management in tree crops integrating plant, soil and social sciences. Dr. Khalsa has authored various papers on agricultural nitrogen use.

Stephanie Tatge completed her M.S. in International Agricultural Development at UC Davis in 2018, where her thesis leveraged spatial analysis to investigate social networks and diffusion of information among farmers. She is now a Research and Outreach Specialist at the Freshwater Trust in Sacramento, CA.

Liza Wood is a PhD student in Ecology at UC Davis, with a Designated Emphasis in Computational Social Science. Her dissertation focuses on governance of seed systems for impacts on biodiversity and socialecological resilience, in the context of climate change. Liza also works on agricultural policy and farmer behavior in California, and the use of science in environmental policy.

Molly Sears is a PhD Candidate in the Department of Agricultural and Resource Economics at the University of California, Berkeley. Her research is largely centered at the intersection of agriculture, environmental quality, and policy. Molly's recent papers include work on recycling policy, groundwater salinity, and nitrogen management.

Patrick H. Brown is a professor of Plant Sciences in the Department of Plant Sciences at UC Davis. His research focuses on the function and transport of nutrients in plants and the management of nutrients in agricultural ecosystems. Dr. Brown has contributed significantly to advancing research in his field and is dedicated to communicating agronomic research through a robust and applied extension program. 